\title{
Is Takashi Murakami's Art an Exploration of Symbolism?
}

\author{
Xiaoming $\mathrm{Hu}^{*}$
}

International department, Peking University Experimental School, Jiaxing, Zhejiang 314050, China, 1312877309sabrina@gmail.com

\begin{abstract}
Looking at all kinds of art in general, contemporary art would be the most distinctive one. It is completely opposite to classical art as an immature system, with a number of possibilities on the use of media and emotions expressed by the art. In this paper, I am trying to figure out what is associated with Takashi Murakami's work. Among all the papers studying Murakami's art, they had concluded his work is exactly related to consumerism. Nevertheless, it is clear that the relationship with symbolism is an important aspect for exploring his art, which hasn't been discovering yet. In this

way, I did some research and gathered secondary sources from online databases and websites. Takashi Murakami, has always been considering a contemporary artist who blur the line between high and low art, but also well known as a "businessman". This is why I am interested in finding out another aspect that is associate with Murakami. After the precise analysis of information I have found, my hypothesis on symbolism was correct, his works are more than just waiting for a sale, but having bigger value on the message he wants to convey. Overall, this paper is not only discovered Takashi Murakami, I choose this artist to find the rebellious in modern artworks and classic artworks.
\end{abstract}

Keywords: Pop Art, Consumerism, Symbolism, Takashi Murakami.

\section{INTRODUCTION}

In the art review, you can see people raised up questions like, "Is this art really worth this amount of money?" "What influenced this artist to create work like this?". However, for this artist, people are more concerned about the first question than others. Takashi Murakami is an artist who is "famous" in the different areas he is working on. He has been seen as a consumerism artist and criticized for that for a long time, but very little is currently known about his work related to other aspects. Therefore, the purpose of this literature review is to clarify the possibility that Akashi Murakami's work is in fact related to symbolism. The concepts of studying the relationship between Murakami's work and symbolism are central to discussing the collision between the value of "Super flat" where is the modern art region with the traditional, classical art[1].
Japanese artist Takashi Murakami is a well-known contemporary artist for his distinctive style of paintings and sculptures. Murakami is a major artist within the field of Super flat, which is necessary here to clarify exactly what is meant by super flat. This concept is promoted by Takashi Murakami which includes any kind of art form that is flatted, such as graphic art, animation, or art in 2D. Few factors that help Murakami to support super flat are referring to the traditional Japanese painting and Ukiyo-e that is done in the Edo period in Japan. One of the common of Asian fine art in ancient times is they do not have perspective, you cannot identify which object is closer or further when they are flatted. From them, Murakami derived from traditional artworks to form beauty by lines.

To find out more inspiration for his work, I traced back to his early life. From a brief biography of Takashi Murakami, I learned that his enormous passion for art comes from his mother, who is an art craft man. Besides that, his parent asked him to do reflections for exhibitions they have seen. 
It is not hard to spot the war element in Takashi Murakami's work, which is highly affected by the notion that his mother instilled in him, the great damage that WWII caused on Japan is everywhere, this would be the biggest influence that makes anti-war became a frequent idea that appears in his art. Except for the impact of his long term study on nihonga and modern European art, he is fascinated about Japanese animation, he even claims that there is a link between the otaku subculture directly to post-WWII Japanese society[2].

The first critical point in his art evolution is the meeting with Joseph Beuys. The dismissive attitude of this artist spur on the critical mindset of Murakami to the western art market. Start from that, the element uses in his work has changed. In order to discover the relationship between Japan and America, Murakami began to use cute icons to show a combination of culture, characters in animation with a higher conception like the catastrophe Japan has been through. In 1994, Murakami got his second chance, with the chance to New York, he absorbed more knowledge and skills from this environment with diversity. Nevertheless, he feels stressed and lonely when he tries to follow the steps of others. To change his circumstance, he realizes the only way to succeed is to find his own unique style and put away the prejudice he had. Murakami finally embraces his Japanese identity and slowly formed his style of art with the assimilation of otaku culture. This move is extremely significant to his career, with creations inspired by this self-awaken, Takashi Murakami began to gain a little fame in the art world. Like a chain reaction, this pushes him to founded his factory for making art, equipped with screen printing skills for large-scale artmaking. He initiated to expand his field in commercial, merchandise, and do collaborations with fashion brands. Although he has standing in the spotlight of the entire world, that he even thinks he is not Japanese anymore, he still worried about what is happening in his homeland. 2011, when the Great East Japan earthquake and tsunami happened, the sorrow makes him create for those life buried down the ground, with his audiences could understand the pain and grief he had. Everything that is been stated so far explains the mixed art genres and various elements in his work, such as Japanese anime icons, anti-war themes, an oriental religion[3].

\section{DEFINE CONSUMERISM}

Consumerism has been a controversial tag on Takashi Murakami. There are many comments on the relationship between the fame of his art and consumerism. The most common critical point is discussing whether he is an artist or a businessman. To interpret why would consumerism promotes his artwork, understand the meaning of consumerism would be the first step. According to Kotler, "Consumerism is a social movement seeking to augment the rights and power of buyers in relation to sellers" [4]. This indicates we can have two ways to understand consumerism in art. In a negative way, consumerism in art can turn art into a product. This may excessively exaggerate its original value or reduces the value it should have if the workers have a deep conception of it. On the other hand, these pieces end up in private collections by selling the price people think it is worth because the consumer would take this as a symbol of their status. What is more than that, this deprives opportunity of more people to admire this work of art. In a positive way, consumerism in art can be a good way for artworks to have more audiences, it becomes more approachable through different media, it would not just be shown for a certain group of people, but enjoyed by everyone. Artworks can be printed into postcards, souvenirs, and even made into little toys, this partly fulfills the desire of customers to own the work [5].

\section{What is the relationship between Takashi Murakami and Consumerism?}

Art critic Jonathan Jones once said "Pop Art taught everyone to enjoy money and the mass media."[6], this may explain why Takashi Murakami is described as eastern Andy Warhol, not just the way they create those repetitive works, yet Murakami learned how to use consumerism to help his art. So I would list three-point to demonstrate why his work is extreme connected to consumerism.

Firstly, in my perspective, Murakami uses consumerism cleverly to advertise and attract more audiences to know him, through exhibitions, animation, movies, and the fashion industry. He takes advantage of this modern society and uses different media to show he is a new kind of artist, whose work is not serious and dreadful, but quite opposite, lively and dynamic. He grabs people's attention so that his art can be appreciated by the public from children to the aged. The artist himself elucidates "that his art is "more about creating goods and selling them than about exhibitions [7].'" Consequently, we can say that the purpose of the bold color and bizarre icons in those frames are just the fuses for him to do business.

Then, as a pop artist, he does not follow the trend or mimic what is fashionable at that time, the real aim of his was to make his work into the model popular, attract the masses to follow him. He creates his own brand, to produce "artworks" sell at different prices from low to high since not many people cannot actually afford a piece of work from Andy Warhol. This shows he really discover the gap in other's cases. Therefore, Murakami does not restrict the definition of art, it can be in any kind of form, even small key chains printed with his paint on could be called a work him [8].

Finally, the reason why this artist likes using factories to make his work is for the high productivity and efficiency of works. There is no doubt, those paintings are produced just for making money. The successes he 
could have today are all because of the hard work of his team of 25, and the utilization of screen printing. Action that could almost be called as being lazy brought him loads of fortune, also pushed him to the cusp of the storm made up with critical reviews on him. This will be a shred of strong evidence pointed out Murakami's relation to consumerism. People were provoked, they would not believe, a man that put art into such a low position, a person who reduces art to a product could get a chance to exhibit his work in the Louvre. According to Guardian's news in 2010, "More than 11,000 people have signed petitions claiming the show is degrading and disrespectful [9]." It reveals that Takashi Murakami's work is truly related to consumerism, whether from the comments of critics, the comprehension of himself, or the public's qualitativeness of his work.

More broadly, there is no necessarily doing more discover with consumerism. Though, researches are needed to determine, is there any aspect that is associated with Takashi Murakami's art? This leads us to explore more possibilities in this region of study[10].

\section{WHERE DID TAKASHI MURAKAMI'S WORK CONNECTED TO SYMBOLISM?}

Symbolism is a movement in the nineteenth century that is crucial to the discipline of literature and visual art. By then, if citizens have dissatisfied with the government, they can not simply declare their mood. On the opposite, they choose to hide these unspoken words into works that can be seen by the public, if someone in the audience realizes the true motivation the person create the work the purpose is achieved, whether it is used to ridicule what is occurring on the society or convey their position on the event [11]. Although the aim of symbolism seemed contradictory to me, you can express your thought secretly with the symbol representing, still, it can be recognized as symbolism while you have no intention to add meaning to an object. With the inherent impression we have about Takashi Murakami, symbolism has been the part that ignored in his art. In fact, symbolism plays a crucial role in Murakami's work. We can tell that by elements in his work that are strongly affected by his personal experiences. For instance, Mr.DOB is the icon created after a long-term reflection, he said that this image is the self-portrait of himself, also the portrait of the Japanese. Yet societies never pay attention to the inner meaning of the work but seen them as gimmicks to get the sight of the community. I always believe that any artist has their own reason for creating art, whether it is aggressive or unreasonable, they still have their purpose to make art, which is to break the common rules on artworks. In this way, my opinion differs from the common judgment on Takashi Murakami. This artist has some kind of complexity that made his work have more ways to interpret.

\subsection{Blue flowers and skulls}

The first example of symbolism in The "Blue flowers and skulls" would be a well-known piece of him. Many people like me may not know it is actually an antiwar theme work before the smiling flower became a popular icon in fashion. The painting was built up with a large number of joyful and adolescent flowers put in the frame randomly, additionally terrifying skulls around them. Formed a strong contradiction in the painting while one is lively, the other is listless. The main color tone of this piece is cold colors such as a different range of blue and purple, usually recognizes as a rendering of sorrow and a negative atmosphere. Nonetheless, many interpretations are indicating the flowers are the reflection of the problem on aging society, Japanese anime is also associated with this issue where people are trying to use lovely images to paralysis from reality. Neither western culture nor the concept of Buddha, skulls is the symbol to remind people of their definite death, they are frequently applied in the sixteen to seventeen century "Vanitas" painting, as the style itself is to warn us that everything is nonexistent in the face of death. As a result of comprehension, the archetypal flowers are the population who do not want to face the reality while the truth is in front of them. This again specifies the blindness of humans when they are willing the ignored the actuality[12].

\subsection{Arhats}

The second example would be the most astonishing one, called 500 arhats. It is one of the pieces in a series of paintings that is depicting the religious story and mortality in disasters. The key icon of the work is arhat. Arhats are monks that advanced their practice path for a long time, yet complete the Buddhahood. It can be simply understood as followers, they are the closest people to Buddha. In some oriental religious myths, arhats would reveal and help suffered creatures when tragic disasters happened. "500 Arhats" is a hundredmeter artwork that Takashi Murakami has ever made, on the huge scale of the work we can see arhats in big or small shapes, where the biggest, conspicuous four represent "the Chinese guardians of the Four Celestial Directions". Considering Buddhism had a profound impact on Japan during the seventeen to the xnineteenth century, Murakami uses these elements in this monumental work made for the Great East Japan earthquake and tsunami in 2011. This explicit the depressive atmosphere in the picture and the weird arhats make us feel the limitations of humans in the face.

\subsection{Little Boy}

As the final example is the most controversial work, a war theme picture named little boy. It was first display in Japanese society by a banner in 2005 . The little boy is 
a code name for a kind of atomic bomb, so the title already explains the main message it is telling us about- the atomic bombing in Hiroshima. Takashi's childhood experience would be a great inspiration on creating series of work that is relevant to post-war Japan, not mentioning the otaku culture that is engaging in. Every character looks adorable and peaceful, this is highly influenced by the subculture in Japan. Kawaii is used to describe things that are extremely cute in Japanese, but in Murakami's work, Kawaii is used as the mask for cruelty and concern of the dark side. Just like the cute icons in red and black shapes represents the mushroom clouds caused by the bomb exploding. In this way, I suppose Murakami has a better motive for spreading his belief or making a statement by this media than just making a profit from them.

\section{CONCLUSION}

The main goal of this study was to determine Takashi Murakami's work is related to symbolism but not only consumerism. Personal experiences led him entered a different path and headed to both consumerism and symbolism, by studying his career route, I discovered various inspirations for him. He had a tough time at the early age of his career life, while he did not found where he belongs until he turns his goal on artmaking onto money, he realizes an artist can not live without financial support. Fortunately, he found his own style after his study on diverges art styles then concentrate on super flat. A granted of his painting are affected by his mother's teaching, the national sentiment is also inherited and enhanced from her. This thereby inspiring him to focus his work on the war-related themes, using Japanese otaku culture as symbolism to criticize how badly Japan has been harm during WWII when the cruelty of reality is opposite from the cuteness of cartoon characters. In the work "Little Boy" He put Japan into the position of a victim, use this to Increase his exposure and influence, in this way he advertises himself, keeps reinforce his influence on business. After all, we cannot deny there are meanings in his work that he wants to tell the world, without the implication of that artwork, he cannot add value to them if they are just ordinary manga. There are criticize on him because he mixed art and consumerism, but this is nott an belittle on art, it is a way he makes art more approachable, they are not high above anymore, from children to old people, they can enjoy this art and also feel the live and the thriving of variation art in the modern world, it can be in any form from a scarf to the painting.

In conclusion, the most obvious finding to emerge from this study is the Symbiosis of Symbolism and consumerism in Murakami's work. He uses symbolism to draw people's attention, whereas they are both adding value to the business of Kaikai Kiki. The relation of symbiosis provides him a specialty identity as a businessman and artist at the same time. In the art world, many of them would hire experts to get them famous, but Murakami did all this by his ideas and his team. Consumerism helps him build a special status and promote his "super flat". This pushes the flourishing of his trade. On the other hand, symbolism is really making a difference for him to get exposure and let his thoughts and the perspective to the world spread more broadly.

\section{REFERENCES}

[1] "Superflat Movement Overview." The Art Story. The Art Story, 2015. https://www.theartstory.org/movement/superflat/.

[2] Borggreen, Gunhild. "Art and Consumption in Post-Bubble Japan." Consuming Life in PostBubble Japan, April 15, 2018, 175-94. https://doi.org/10.2307/j.ctv56fgjm.13.

[3] "Takashi Murakami." The Art Story. The Art Story, 2017. https://www.theartstory.org/artist/murakamitakashi/.

[4] Kotler, Philip. "What Consumerism Means to Marketers." Harvard Business Review 50 (2020): 48-57.

https://www.scholars.northwestern.edu/en/publicat ions/what-consumerism-means-to-marketers.

[5] Buskirk, Richard H., and James T. Rothe. "Consumerism - an Interpretation." Journal of Marketing 34, no. 4 (October 1, 1970): 61-65. https://doi.org/10.1177/002224297003400410.

[6] Jones, Jonathan. "How Art Killed Our Culture." the Guardian. the Guardian, March 6, 2009. https://www.theguardian.com/artanddesign/jonatha njonesblog/2009/mar/06/capitalism-culture-artmarket.

[7] Staff, WIRED. "The Two Faces of Takashi Murakami.” WIRED. WIRED, November 2003. https://www.wired.com/2003/11/artist/.

[8] Bisbee, Abigail. "Commercialism and International Art World: Takashi Murakami and the Rise of the New International Artist | CCTP725: Cultural Hybridity: Remix and Dialogic Culture." CCTP725: Cultural Hybridity and Dialogic Culture Professor Martin Irvine. Communication, Culture \& Technology Program Georgetown University, December 14, 2013. https://blogs.commons.georgetown.edu/cctp-725fall2013/2013/12/14/commercialism-andinternational-art-world-takashi-murakami-and-therise-of-the-new-international-artist/.

[9] Davies, Lizzy. "Takashi Murakami Takes on Critics with Provocative Versailles Exhibition." the Guardian. the Guardian, September 10, 2010. 
https://www.theguardian.com/world/2010/sep/10/t

akashi-murakami-versailles-exhibition

[10] Larceneux, Fabrice, Florence Caro, and Anne

Krebs. "The Reaction of Visitors to Contemporary

Art in a Classical Art Institution: A Louvre

Museum Case Study." International Journal of

Arts Management 18, no. 2 (2016): 4-13.

https://www.jstor.org/stable/44989647.

[11] Balter, M. "ORIGINS: On the Origin of Art and Symbolism.” Science 323, no. 5915 (February 6, 2009): 709-11.

https://doi.org/10.1126/science.323.5915.709.

[12] "Takashi Murakami Artworks \& Famous Art." The Art Story, 2012.

https://www.theartstory.org/artist/murakamitakashi/artworks/. 